This article has been scanned by iThenticat No plagiarism detected

Volume 3, Issue 4, August 2021

p. $1-11$

\title{
ONLINE EXAM ANXIETY IN BLENDED LEARNING PROCESS FOR MIDDLE SCHOOL STUDENTS IN PALESTINE (HITTEEN PRIMARY SCHOOL AS A SAMPLE)
}

http://dx.doi.org/10.47832/2757-5403.4-3.1

\section{Jafar Muhammad Aref JARADAT ${ }^{1}$ \& Fawqia Muhammad Aref JARADAT ${ }^{2}$}

\begin{abstract}
:
This study aims at identifying the level of anxiety from online examination in the blended learning for middle stage studants in Palestine "Hitten primary school as a study case".

This sample consists of 272 students from this school chosen simply and randomly based on ascale of online examination anxiety prepared by Mr.Atiyya Abu Al-sheikh. Some significant results came out from this study: First, there is a big level of anxiety when sitting for online exams during the process of blended learning. Second, there is statistical significance when considering the class variable. Thirdly, it is noticed that there is also statistical significance when considering the device used. Some necessary recommendations are given and the most important one is to adopt a councelling supporting blended program to reduce the level of stress and anxiety.
\end{abstract}

Key words: Anxiety, Online Exam Anxiety, Blended Learning, Primary School.

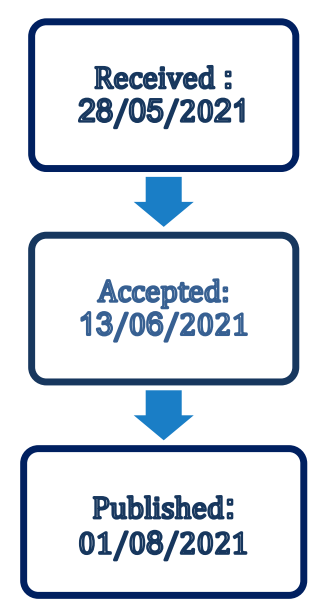

\footnotetext{
${ }^{1}$ Researcher, Mohammed Alkhames University, Morocco, jafar m 76@hotmail.com, https://orcid.org/00000002-2180-9234

${ }^{2}$ Researcher, Ain Shams University, Egypt, jaradatfawqia@hotmail.com, https://orcid.org/0000-0002-8502-253
}

Copyright $(\odot$ Published by IJHER Journal, www.ijherjournal.com Rimar Academy, Fatih, Istanbul, 34093 Turkey

All rights reserved 


\title{
ONLINE EXAM ANXIETY IN BLENDED LEARNING PROCESS FOR MIDDLE \\ SCHOOL STUDENTS IN PALESTINE (HITTEEN PRIMARY SCHOOL AS A \\ SAMPLE)
}

\section{قلق الاختبار الإكتروني في عملية التعليم المدمج لاى طلبة المرحلة المتوسطة في فلسطين (مدرسة حطين الأساسية أنموذجيماً)}

\author{
جعفر محمد عارف جراد ادات 3 \\ فوقيه محمد عارف جرادات جرادات
}

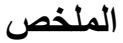

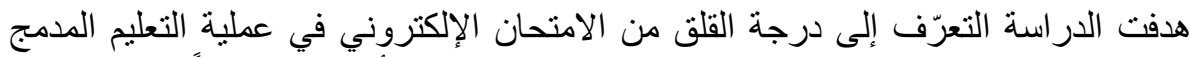

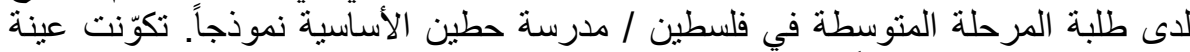

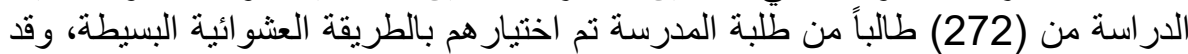

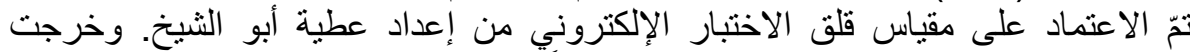

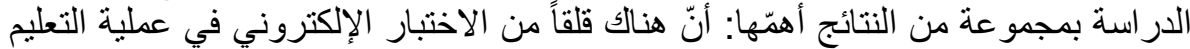

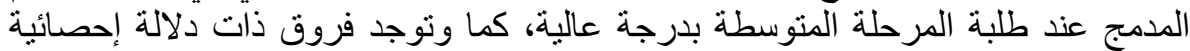

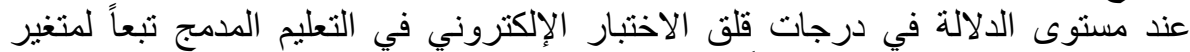

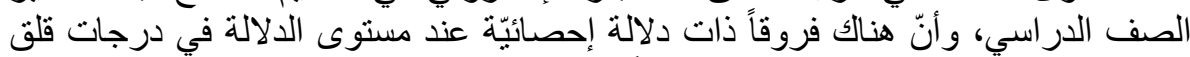

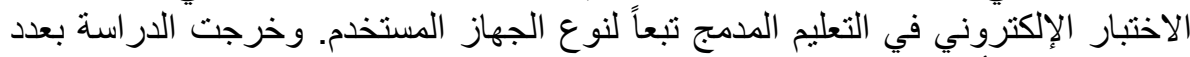

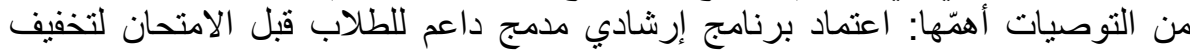

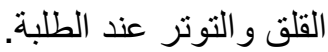
الكلمات المفتاحية: القلق، قلق الاختبار الإلكتروني، التعليم المدمج، مرحلة المدرسة المنوسطة.
\end{abstract}

المقََّمة: يو اجه التعليم المدرسي و العالي تطورات وتغيرات سريعة وحديثة، لذا فقد ظهرت العديد من المستحدثات التكنولوجية التي

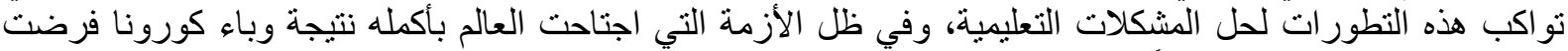

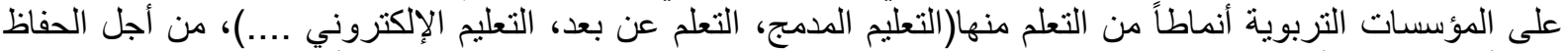

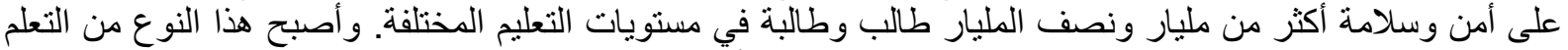

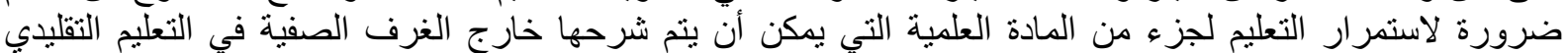

الوجاهي.

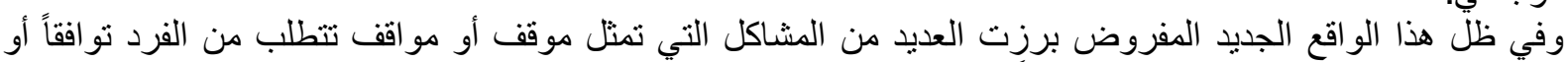

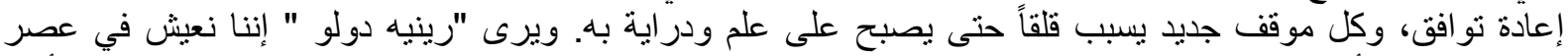

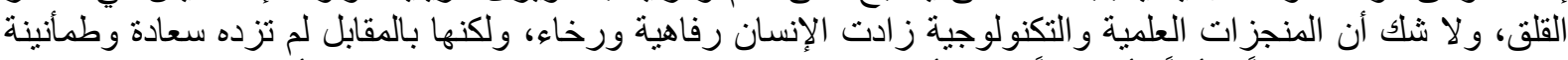

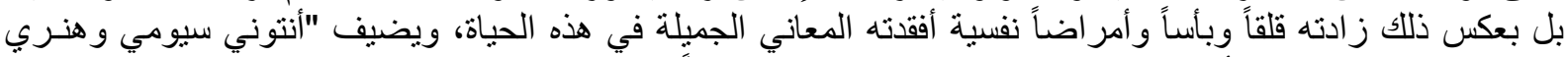
بيتر" في عنوان لهما "الأمل في عصر القلق حيث يقدمان توصيفاً للعديد من "التقنيات " التي ترمي إلى تحسين حياة الأفر اد وجعل العالم أكثر إنشعاعاً. في العصر التكنولوجي الذي نعيشه، " عصر القلق" هناك العديد من التحديات التي نعيشها، ولعل أبرز مظاهر هذا التها التحدي

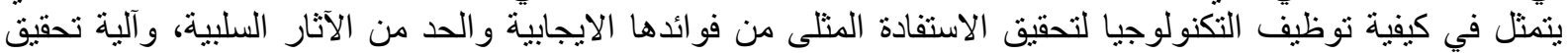

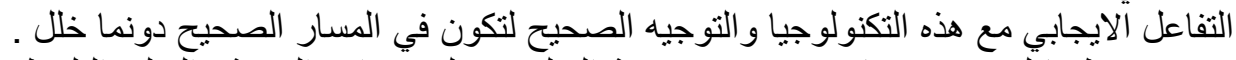

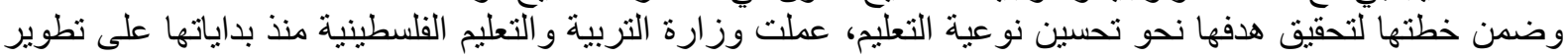

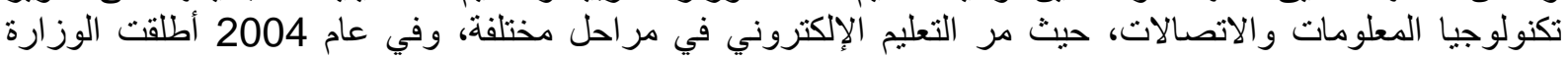

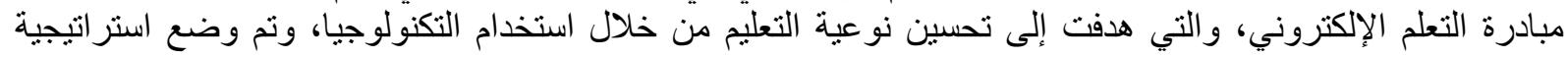

jafar m 76@hotmail.com الباحث، جامعة محمد الخامس، المغرب،

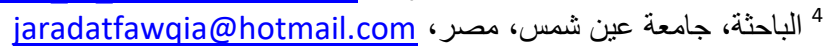


للتعليم الإلكتروني، ومنذ ذلك الوقت هناك العديد من المشاريع التي ساهمت في تعزيز توظيف تكنولوجيا المعلومات

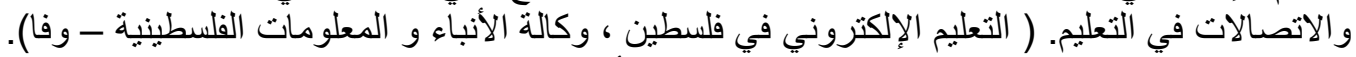

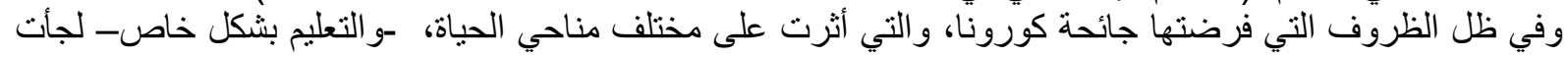

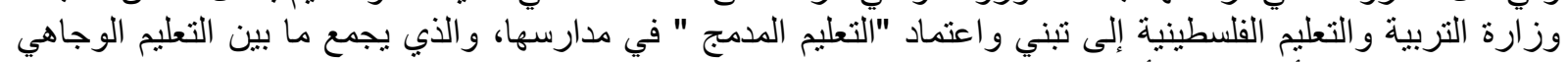

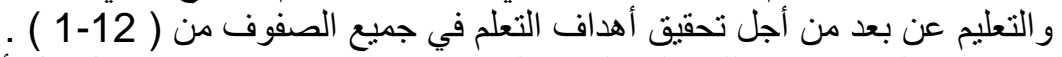

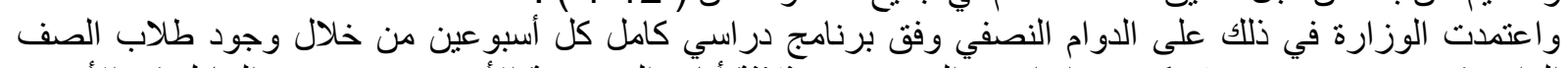

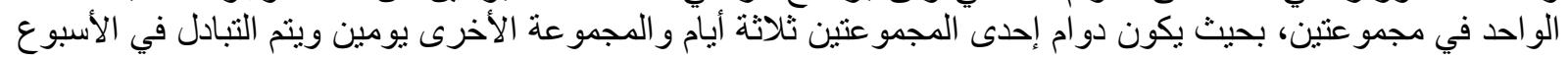

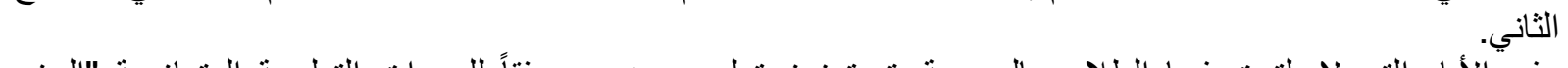
وفي الأيام التي لا يلتحق فيها الطلاب بالمدرسة يتم تعزيز تعلمهم عن بعد وفقاً للوحدات التعليمية المنمازجة "الرزم

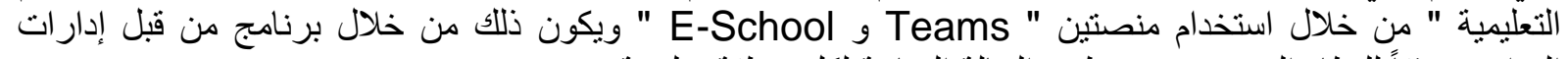
المدارس وفقاً للنظام المدمج حسب تلإل الطور الحالة الوبائية لكل منطقة تعليمية.

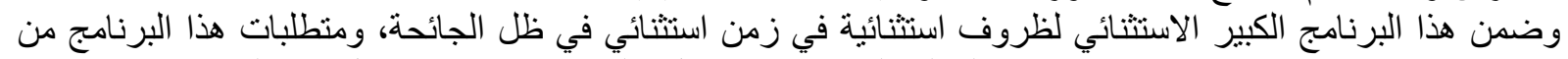

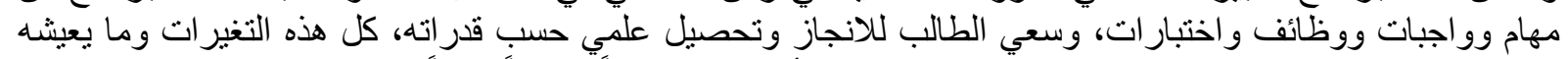

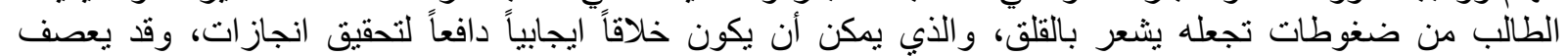

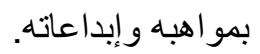
وقلق الاختبار الإلكتروني أحد أنواع هذا القلق، والذي نسعى في دراستنا هذه لقياس مستوياته في عملية التعليم المدمج لاى الدي

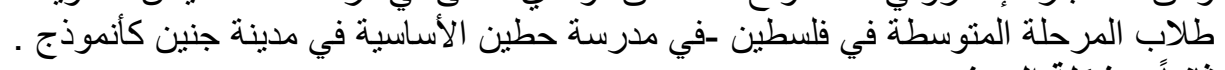

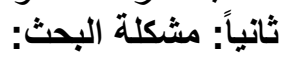

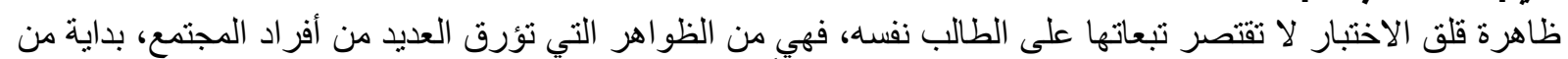

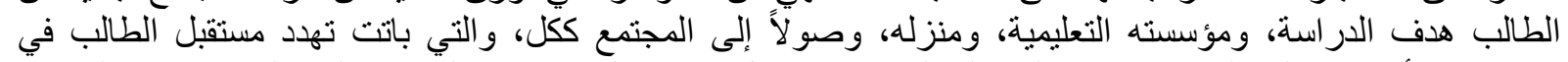

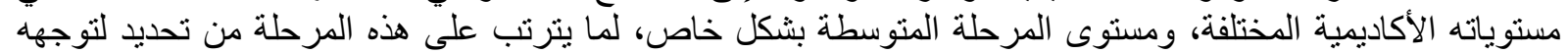

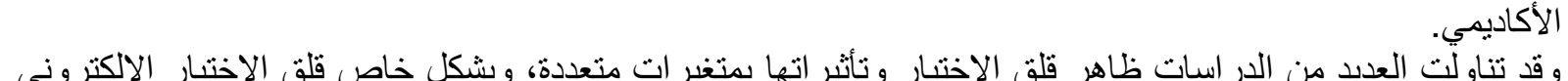
بمتغير ات مختلفة.

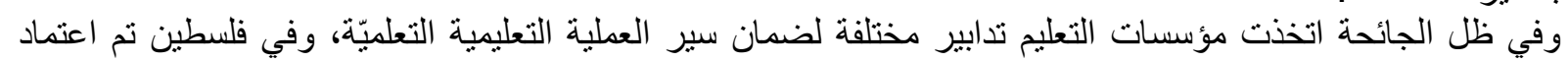

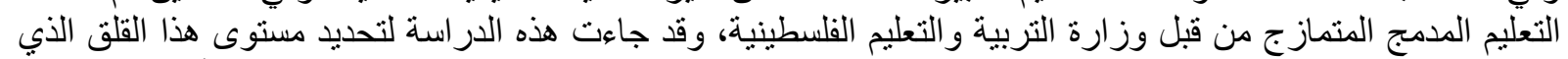

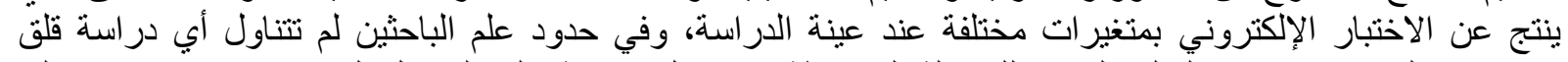

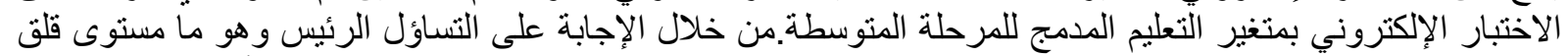

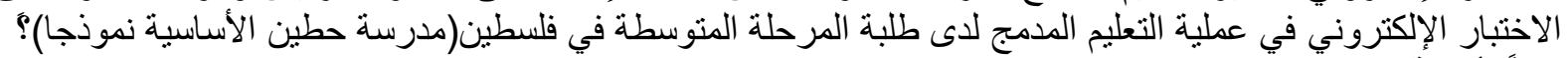

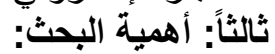
تتضخح أهمية الذراسة في ناحية: ألاحيتين أهمية نظرية وأهمية تطبيقية على النحو الآتي: الأهمية النظرية: النمية:

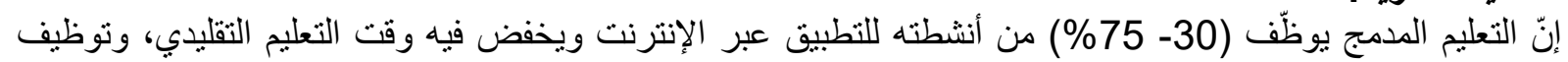

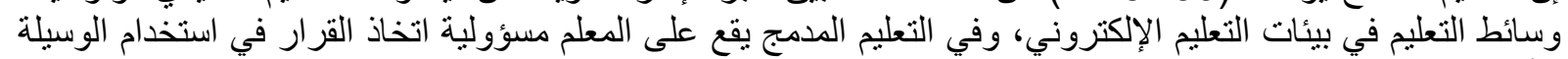

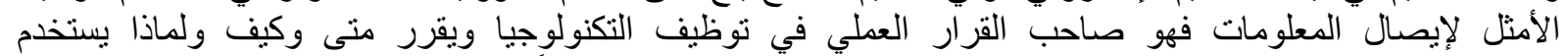

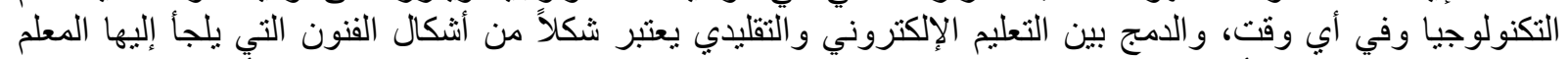

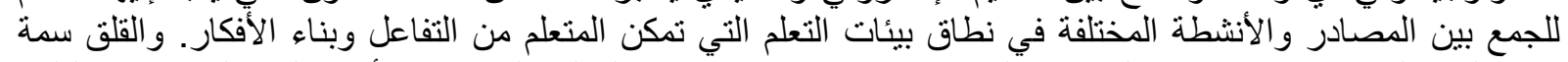

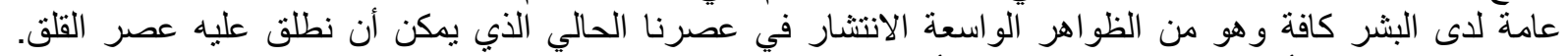

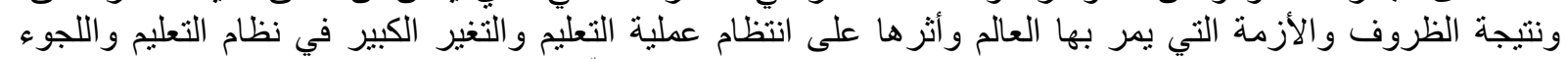

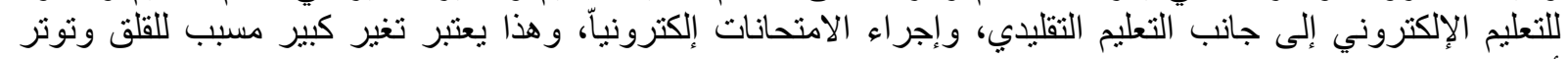
أثناء تقديم الامتحكان.

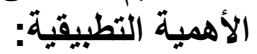
تهنم الدراسة بالكثفة عن مستوى قلقي الاختبار الإلكتروني في عملية التعليم المدمج لأى طلبة المرحلة المتوسطة في

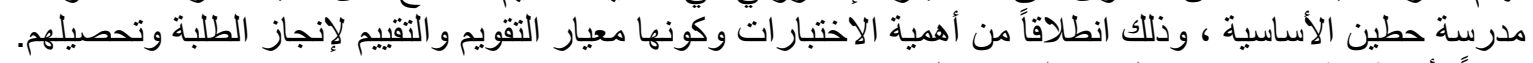

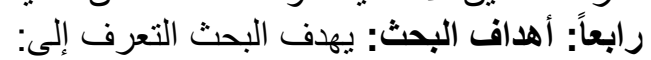
1. معرفة مستوى قلق الاختبار الإلكتروني في عملية التعليم المدمج لدى طلبة المرحلة المنوسطة في مدرسة حطين الأساسية. 2. درجة قلق الاختبار الإلكتروني في عملية التعليم المدمج لاى طلبة المرحلة المتوسطة في مدرسة حطين الأساسية باختلاف متغير ات الدر استة. 


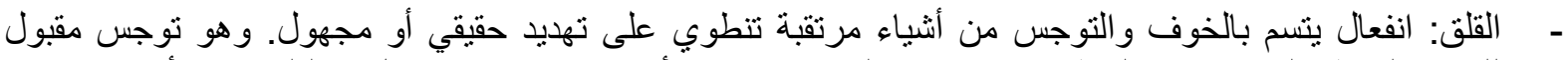

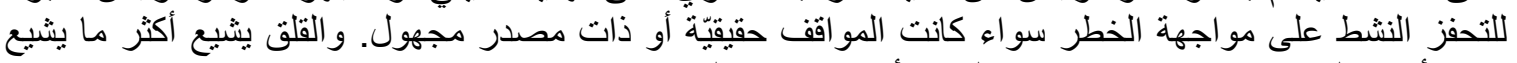

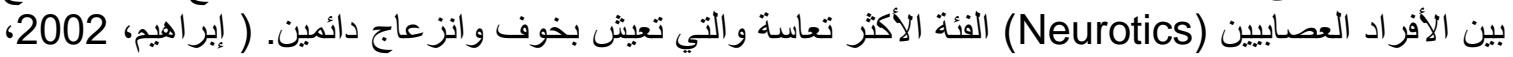

(10, 9

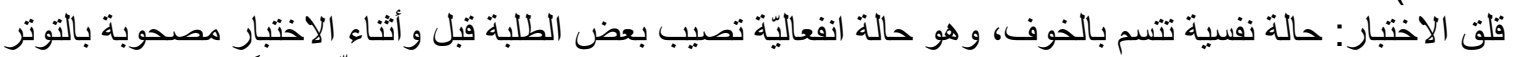

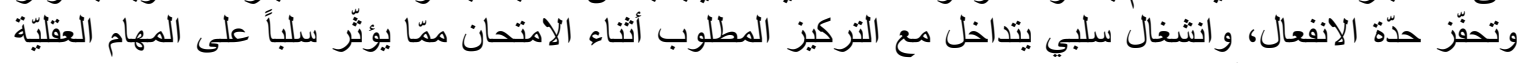

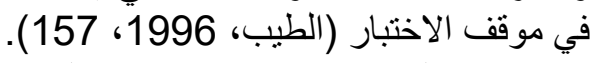

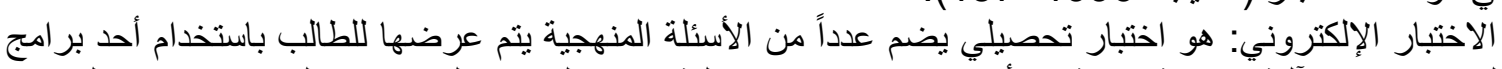

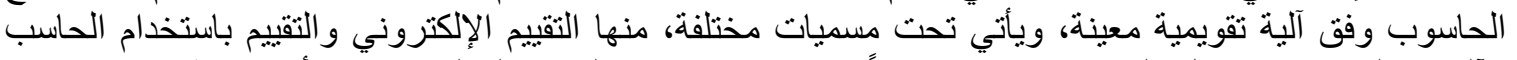

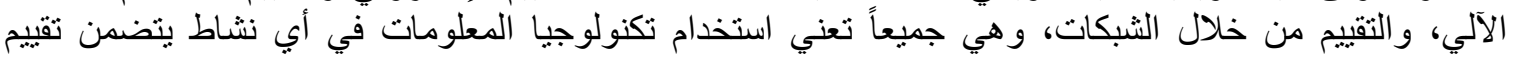

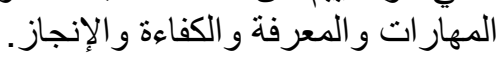

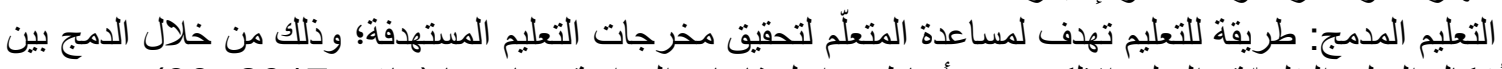

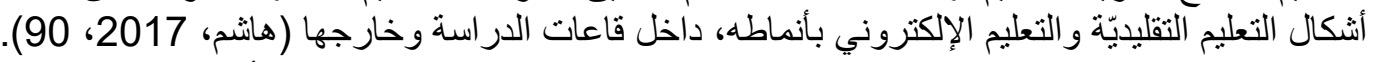

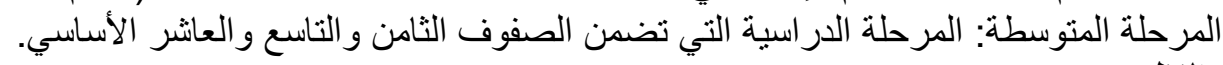
الإطار النظري: المزئ

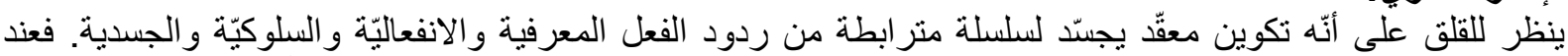

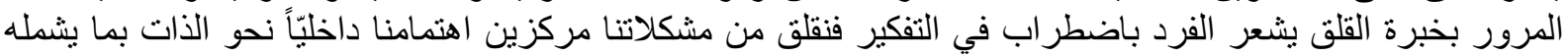

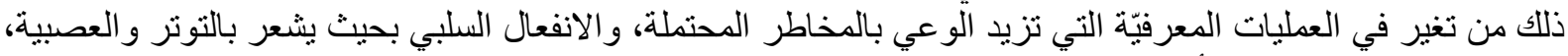

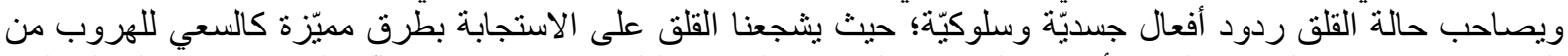

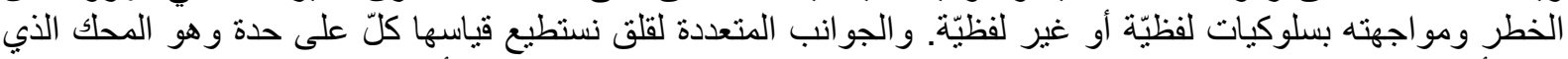

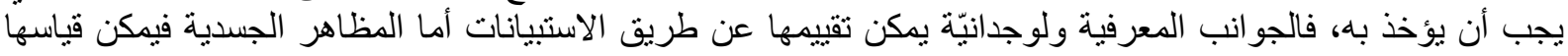

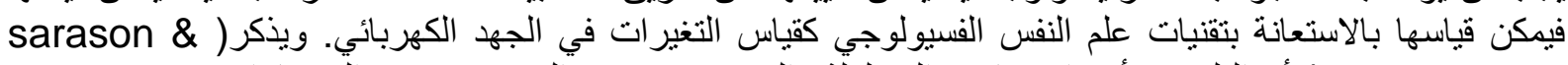

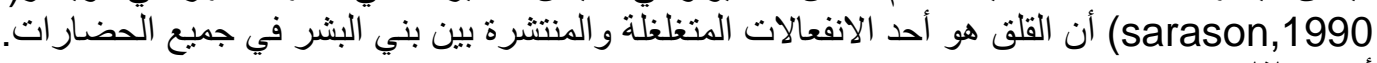
أنواع القلق: (1990

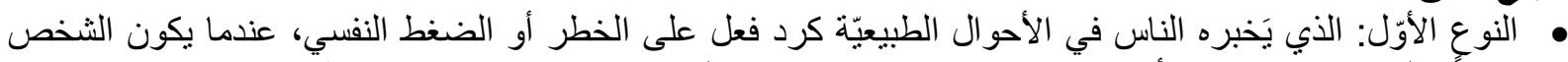

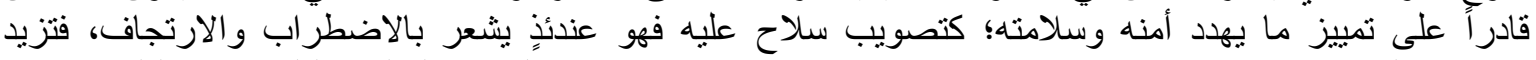

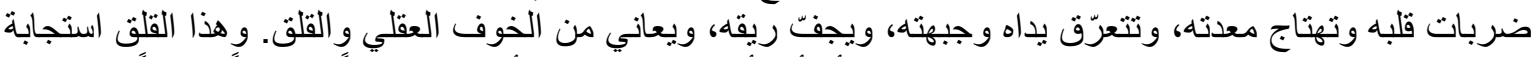

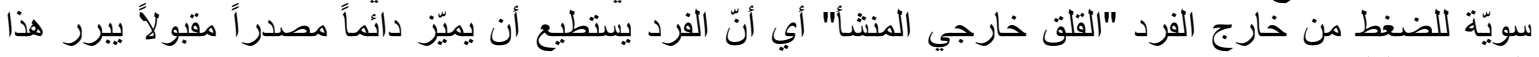
النوع من القلق عند حدوثنه.

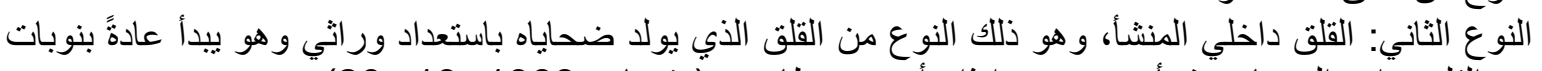

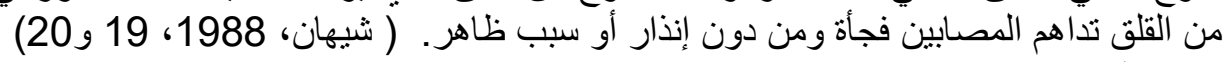

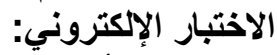

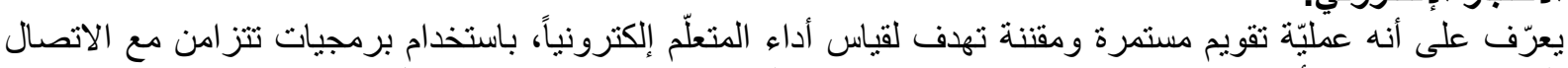

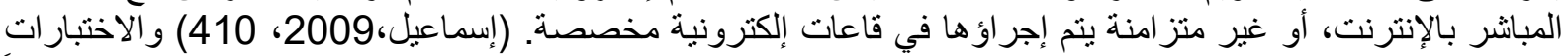

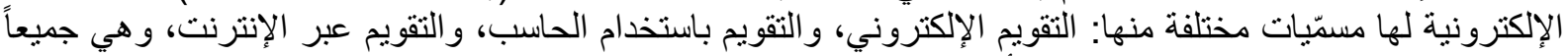

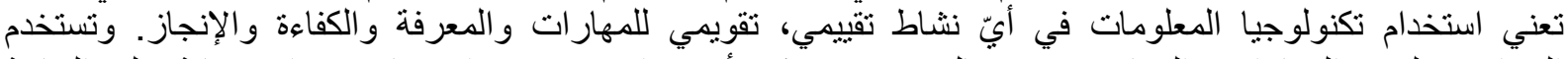

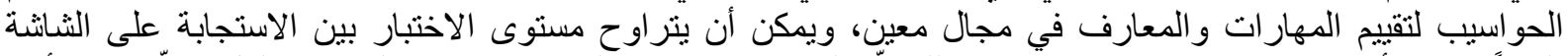

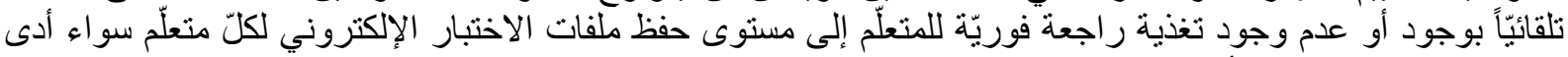

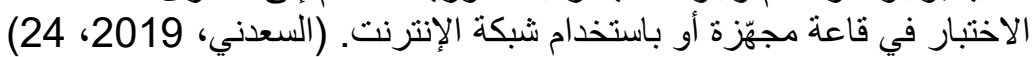

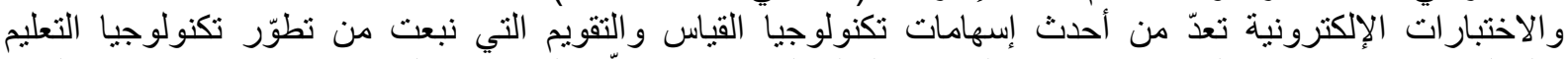

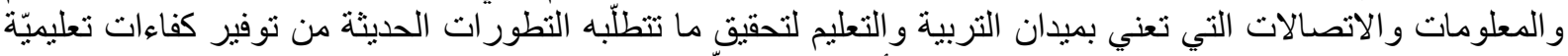

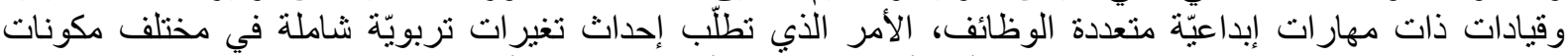

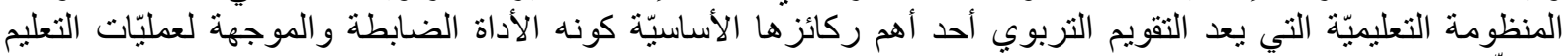

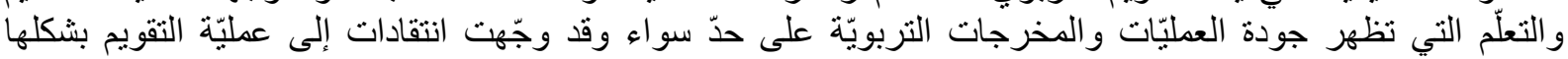




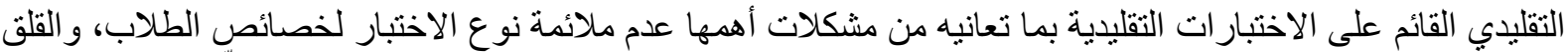

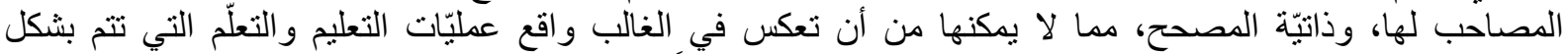

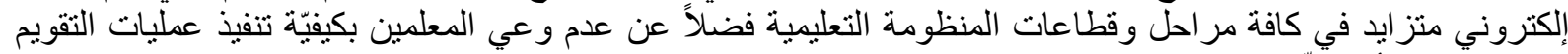

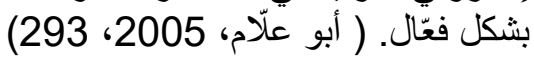

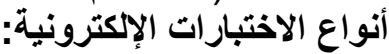

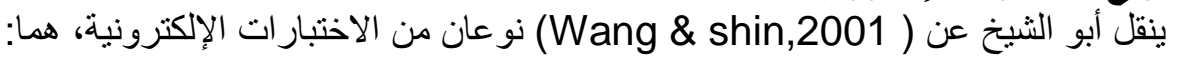

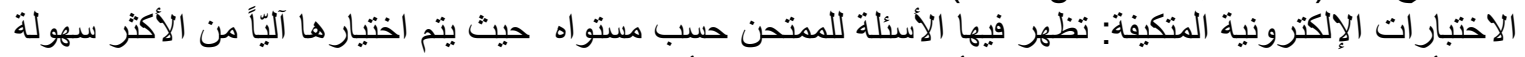

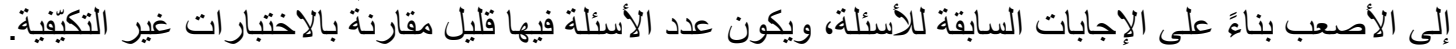

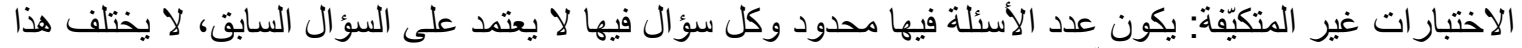

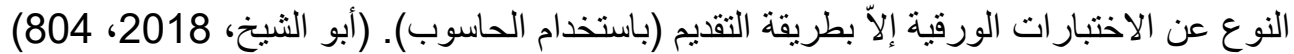

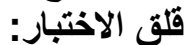

تعدّ الاختبار اتلّات مهمّة لزيادة دافعيّة الطلبة نحو التعلّم واكتشاف المهارات والمعارف الضروريّة، ويقع على عاتق المعلم

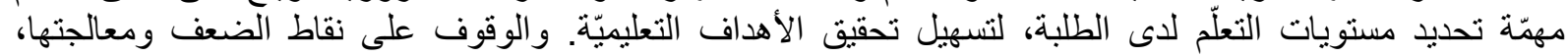

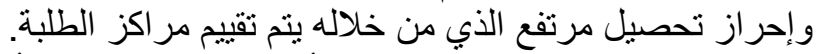

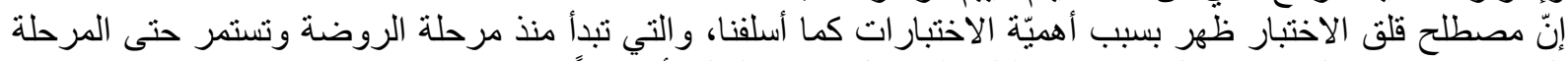

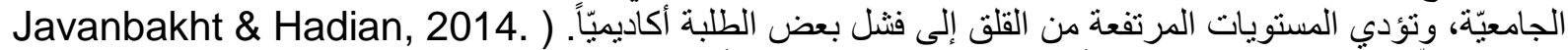

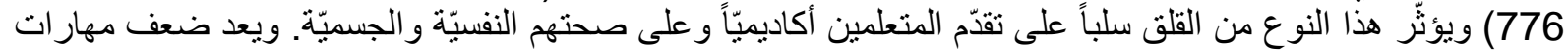

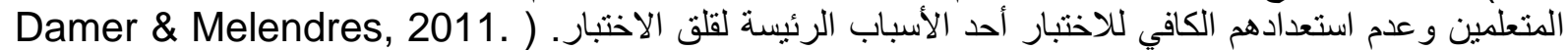

و عند الحديث عن القلق ينظر له بمثابة العامل الأساسي الذي يؤثّر على الطلبة وأسرهم، خصوصاً أيّام الامتحانات من

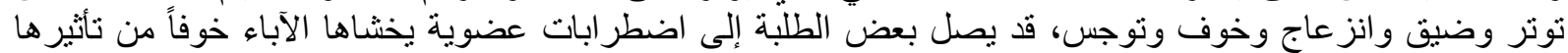

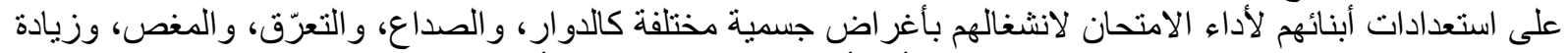

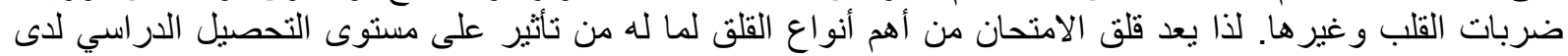

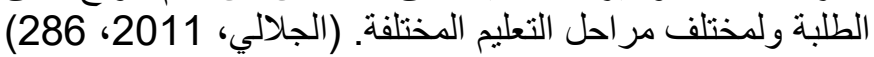

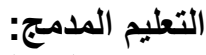

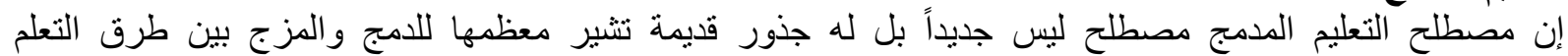

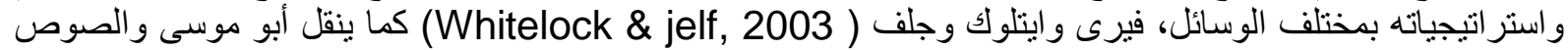

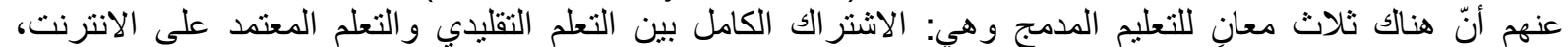

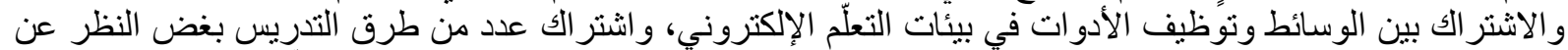

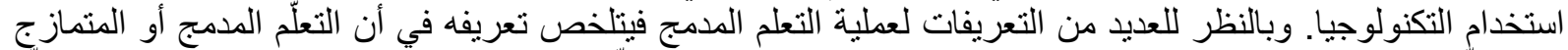

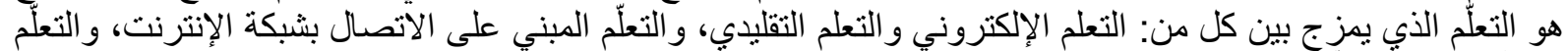

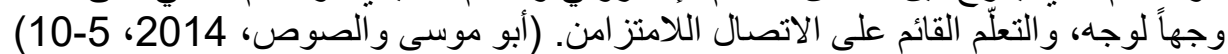

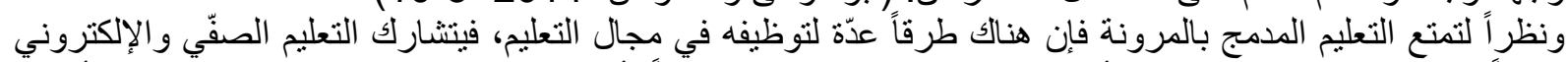

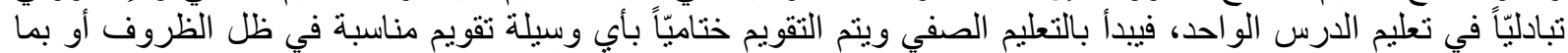

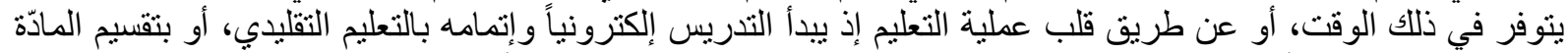

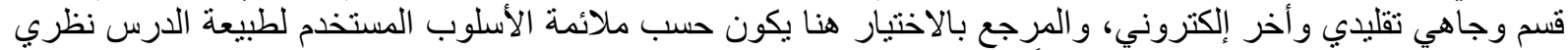

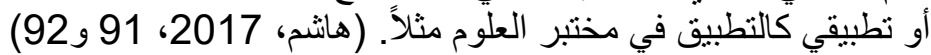

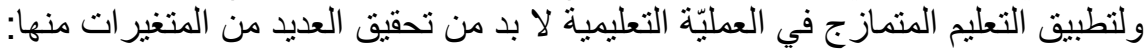
توفير مختبرات حاسوب بشكل ينو افق مع النتائج التي تسعى الأنظمة التعليمية لتحقيقها، ونوفير البنية التية التحتية من

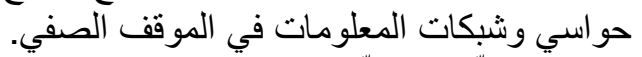
ـ ـ تدريب المعلّم و المتعلّم على المهار في اتل الضروريّة لاستخدام الوسائط المتعددة وتوفير الدورات التدريبية اللازمة لهم. - توفير المناهج التعليمية التي تتوافق وتقنيات التعلّم الحديثة. (قطيط، 2015، 160)

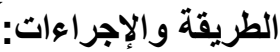

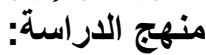

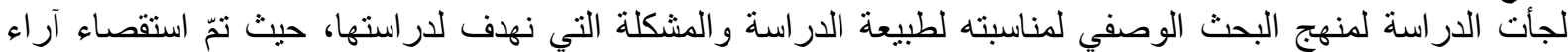
طلبة المرحلة المنوسطة في مدرسة حطين الأساسية كنموذج عن مدارس فلسطين حول القلق من الاختبار الإلكتروني في التي

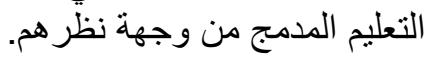


تكون مجتمع الدراسة من طلبة البة مدرسة حطين الأساسية (كنموذج)، و البالغ عددهم ( 2021 (254) للعام الدراسي 20202021. وتكونت عينة الدراسة من (272) طالباً من طلبة مدرسة حطين الأساسية نم اختيار هم بالطريقة العشوائية البسيطة، استبعد منها (3) استبانات لعدم صلاحيتها للتحليل الإحصائي لتصبح العينة (269) طالباً، وييين جدول (1) بلائة توزيع أفراد عينة الدراسة.

\begin{tabular}{|c|c|c|c|c|}
\hline المجموع & النسبة المئوية & العدد & & المتغير \\
\hline \multirow{3}{*}{269} & 38.2 & 104 & العاشر & \multirow[t]{3}{*}{ الصف الدر اسي } \\
\hline & 31.3 & 85 & التاسع & \\
\hline & 29.4 & 80 & الثنامن & \\
\hline \multirow{4}{*}{269} & 71.3 & 194 & جوال & \multirow[t]{4}{*}{ نوع الجهاز المستخدم } \\
\hline & 12.9 & 35 & لاب توب & \\
\hline & 11.8 & 32 & جهاز كمبيوتر & \\
\hline & 2.6 & 8 & تابلت & \\
\hline
\end{tabular}

أدوات الدراسة: مقياس قلث الاختبار الإلكتروني

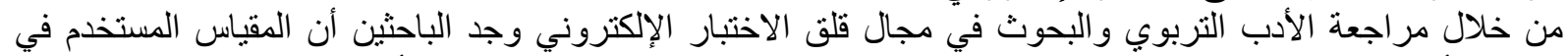

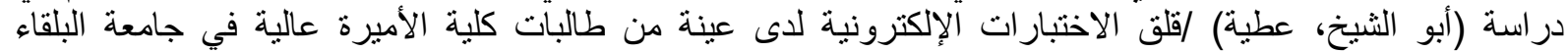

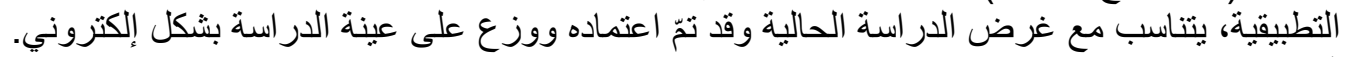
ثبات المقياس: حساب ثبات الأداة عن طريق قياس ثبات التجانس الداخلي (consistency)، وهذا النوع من الثبات يشير إلى قوة

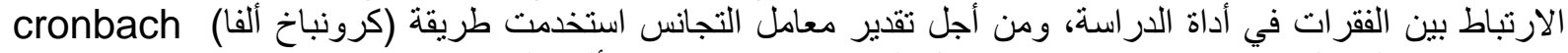
(Alpha) جدول (2) يبين نتائج اختبار معامل الثبات كرونباخ ألفا على مقياس الدراس استة \begin{tabular}{|r|r|r|}
\hline قلق الاختبار الإلكتروني & (2) \\
\hline
\end{tabular}

يتضح من الجدول ( 2) أن قيمة معامل الثبات بطريقة كرونباخ ألفا للمقياس بلغت ( 0.96) وهذا يشير إلى أن الأداة

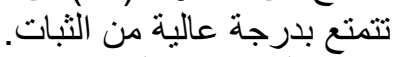

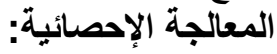

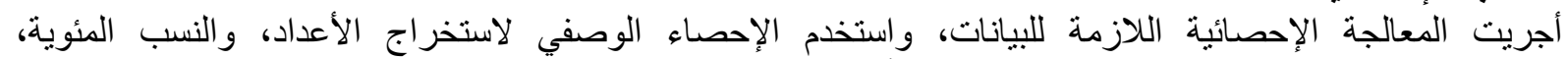

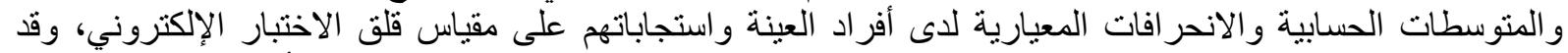

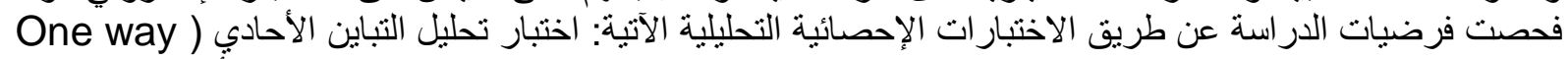

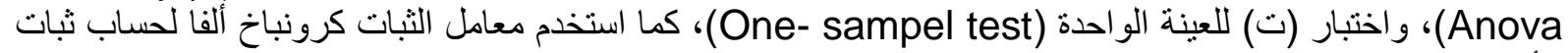
الأداة، وذللك باستخدام برنامج الرزم الإحسنة الإحصائية (spss).

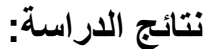
أولاً: النتائج المتعلقة بالسؤ ال الأول الذي ينص على: " ما مستوى قلق الاختبار الإلكتروني في عملية التعليم المدمج لدى

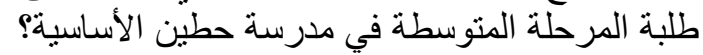

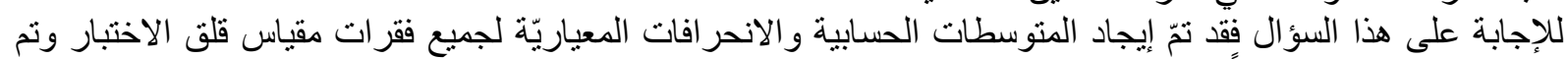

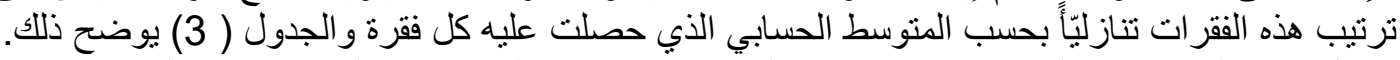

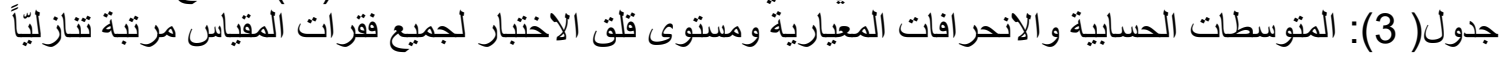




\begin{tabular}{|c|c|c|c|c|c|}
\hline المستوى & 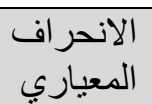 & الحسابي المتي & الفقرة & الرقم & الرتبة \\
\hline كبيرة جدا & .916 & 4.29 & أو أنقطر بالقلق من التيار الكهربائية تعطل جهاز الحاسوب & 16 & 1 \\
\hline كبيرة & 1.032 & 4.14 & و قت أكتر بأن أداء الاختبار الإلكتروني يحتاج إلى & 10 & 2 \\
\hline كبيرة & .900 & 4.11 & أفضل ألكتروني أن لا أنزعج عند تقديم الاختبار & 26 & 3 \\
\hline كبيرة & 1.107 & 4.05 & الوقبب بسرعة و بلا تركيز خوفاً من انقضاء & 28 & 4 \\
\hline كبيرة & .957 & 4.01 & ألفكر كثيراً في إمكانية النجاح في الاختبار ات & 27 & 5 \\
\hline كبيرة & 1.138 & 3.89 & لأل تعكس جنائج الاختبار الإلكتروني مستو اي & 9 & 6 \\
\hline كبيرة & 1.070 & 3.88 & أقدر على أداء عمل جيد في الاختبار & 17 & 7 \\
\hline كبيرة & 1.230 & 3.87 & الإكتروني بالارتباك أثناء تقديم الامتحان & 21 & 8 \\
\hline كبيرة & 1.257 & 3.82 & و غتوقع أن تعليمات الاختبار الإلكتروني صعبة & 1 & 9 \\
\hline كبيرة & 1.194 & 3.82 & من الترقد في أخذ الاختبار الإلكتروني خوفاً & 15 & 10 \\
\hline كبيرة & 1.128 & 3.79 & أعتقأ بأن الاختبار الإلكتروني لا يقيس & 8 & 11 \\
\hline كبيرة & 1.282 & 3.73 & أنشعر بالقلق عند أداء الاختبار إلكترونيا & 5 & 12 \\
\hline كبيرة & 1.232 & 3.72 & باستخدام الحاسوب أركز في الاختبار الإلكتروني & 2 & 13 \\
\hline كبيرة & 1.218 & 3.69 & الثشاشة مباشُرة حل الاختبار إذا كان أداؤه على & 3 & 14 \\
\hline كبيرة & 1.355 & 3.63 & تأدية الامتحان الإرتياح لعدم وجود مر اقب أثناء & 30 & 15 \\
\hline كبيرة & 1.330 & 3.56 & 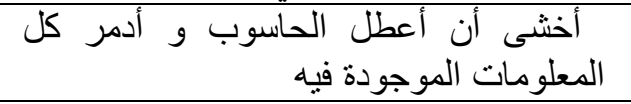 & 14 & 16 \\
\hline كبيرة & 1.258 & 3.56 & الشُعتر بالذعر الثديد أثناء تقديم الامتحانات & 22 & 17 \\
\hline كبيرة & 1.312 & 3.54 & ضغظي النفسي بأداء الاختبار الإلكتروني يرفع & 4 & 18 \\
\hline كبيرة & 1.375 & 3.53 & أرثبرة بأخذ الاختبار إلكترونياً نظر أ لمز اياه & 20 & 19 \\
\hline كبيرة & 1.204 & 3.53 & ألتمتع ب بالتحدي المصاحب للاختبار & 6 & 20 \\
\hline كبيرة & 1.306 & 3.52 & الإلكتروني بقدر اتي الحاسوبية عند أخذ الاختبار & 11 & 21 \\
\hline كبيرة & 1.382 & 3.49 & الإلكترونية أي فائدة في استخدام الاختبار ات & 19 & 22 \\
\hline كبيرة & 1.350 & 3.43 & إلكترونيا بعصبية شديدة عندما أققم اختبارا & 23 & 23 \\
\hline كبيرة & 1.324 & 3.42 & أخفق في الاختبار الإلكتروني & 29 & 24 \\
\hline
\end{tabular}




\begin{tabular}{|c|c|c|c|c|c|}
\hline منوسطة & 1.518 & 3.37 & أوضضل الاختبار الإلكتروني على الاختبار & 18 & 25 \\
\hline متوسطة & 1.254 & 3.33 & الإلكتروني يزيد دافعيتى & 7 & 26 \\
\hline متوسطة & 1.383 & 3.31 & أشتعر بألم شديد في بطني قبل الامتحان & 24 & 27 \\
\hline متوسطة & 1.371 & 3.31 & لا أثق بنفسي عند تقديم الآختبار الإلكتروني & 25 & 28 \\
\hline متوسطة & 1.399 & 3.30 & متمكن حاسو أخذ الاختبار الإلكتروني لأني غير & 12 & 29 \\
\hline 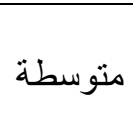 & 1.408 & 3.25 & ألاختبار الإلكتروني لمساعدة مختص بالحاسوب أثناء & 13 & 30 \\
\hline كبيرة & .79421 & 3.6611 & 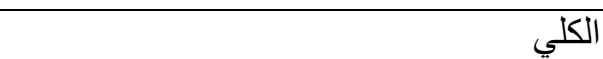 & & \\
\hline
\end{tabular}

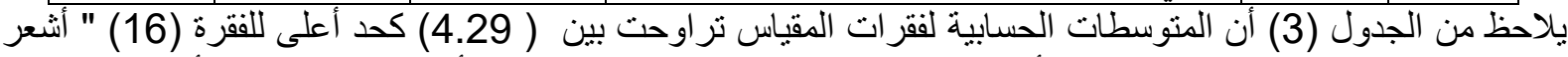

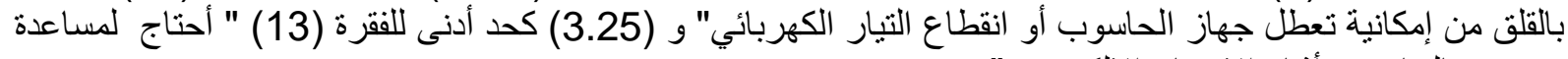
مختص بالحاسوب أثناء الاختبار الإلكتروني".

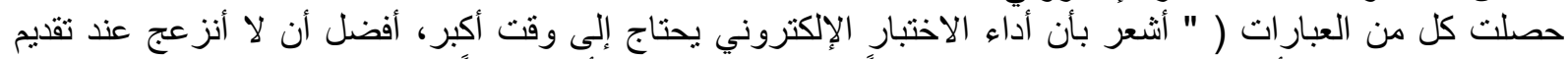

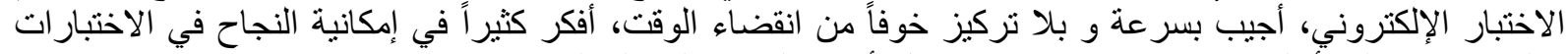

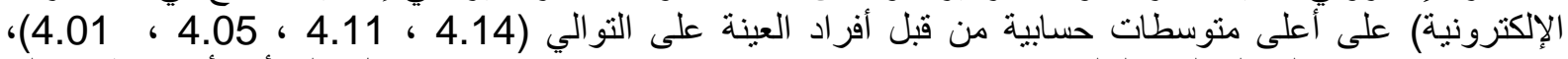

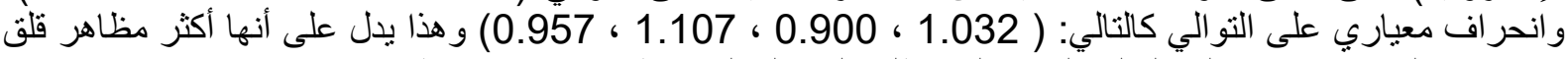
الاختبار الإلكتروني في عملية التعليم المدمج لإى الدي طلبة المرحلة المتوسطة في مدرسة حطين.

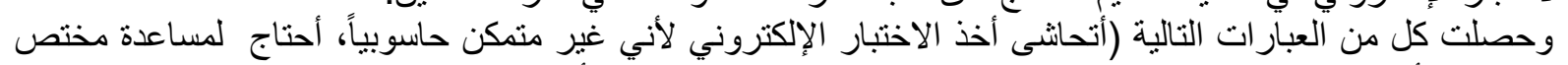

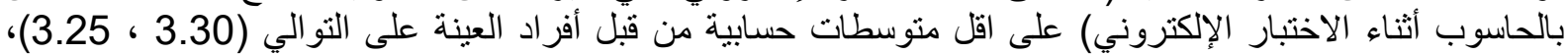

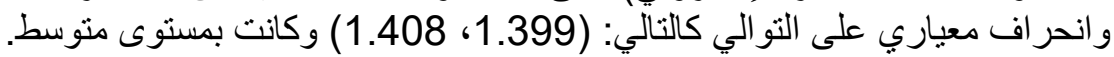

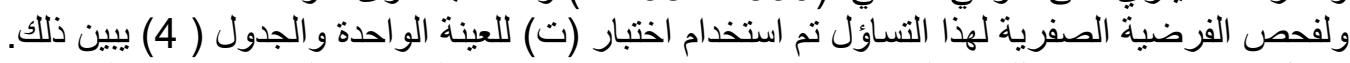

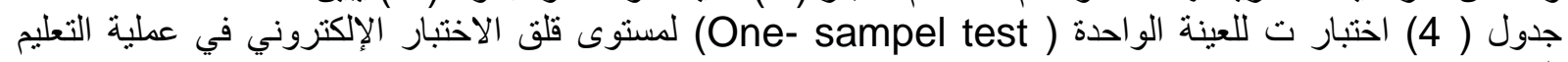

\begin{tabular}{|c|c|c|c|c|c|c|}
\hline الدسلةى المعياري & قالمحسوبة ت ت & الحرجية & الدلالة & الانحر افياري & الحسابي & \\
\hline 0.05 & 74.57 & 268 & 0.00 & 0.79 & 3.67 & الإلكتروني \\
\hline
\end{tabular}

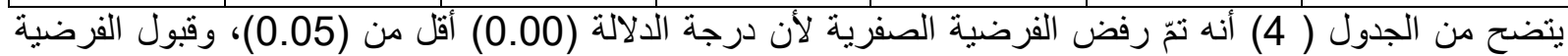

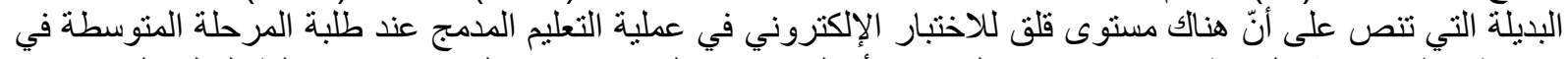

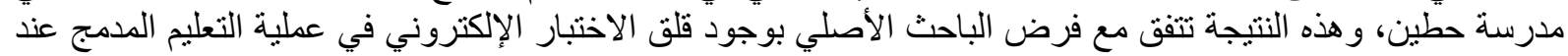

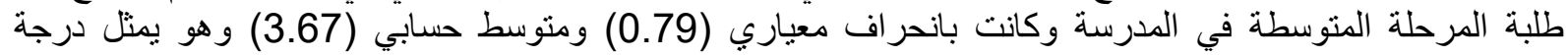

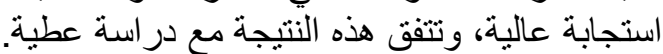

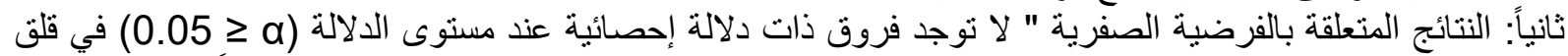

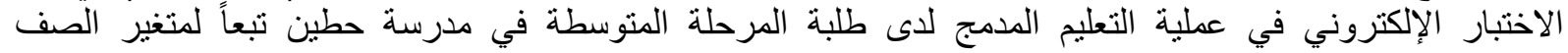

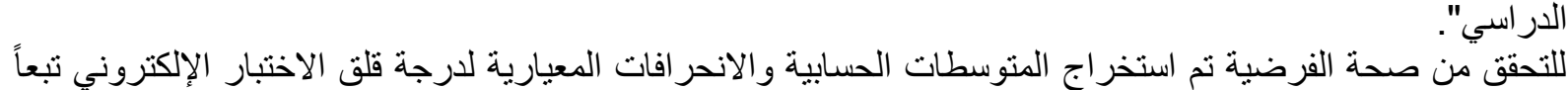

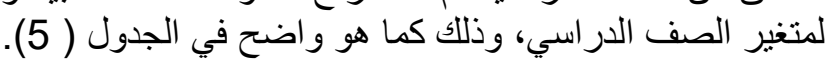

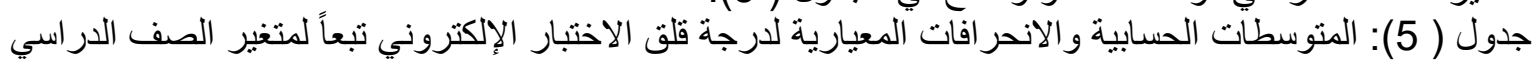




\begin{tabular}{|c|c|c|c|c|}
\hline الانحر اف المعياري & المتوسط الحسابي & العدد & الصف الدر اسي & المتغير \\
\hline 0.686 & 3.24 & 104 & العانشـر & \multirow{3}{*}{ الصف الدراسي } \\
\hline 0.729 & 3.77 & 85 & التاسع & \\
\hline 0.73 & 409 & 80 & الثامن & \\
\hline
\end{tabular}

يتضح من الجدول ( 5) أنّ المتوسط الحسابي لطلبة الصف العانشر (3.24) و التاسع (3.77) وهي نسب منقاربة لحد ما أما متوسط الصف الثنامن كان (5.09) وكان وانت نسبته كبيرة. ولفحص الفرضية استخرجت نتائج تحليل التباين الأحادي كما

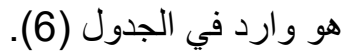

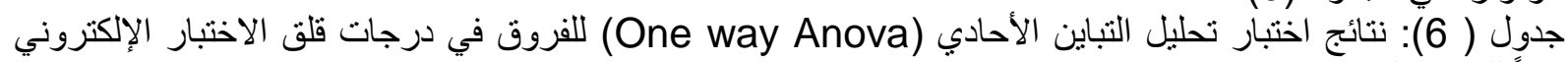

\begin{tabular}{|c|c|c|c|c|c|c|}
\hline الالحصائية & قالمحسوبة ف ف & متوسط & الحرية & المربعوع & مصدر & \\
\hline \multirow{3}{*}{0.00} & \multirow{3}{*}{32.77} & 16.717 & 2 & 33.43 & المجمو عات & \multirow[t]{3}{*}{ الدر اسفي } \\
\hline & & 0.51 & 265 & 135.17 & المجمو عات & \\
\hline & & & 267 & 168.61 & المجموع & \\
\hline
\end{tabular}

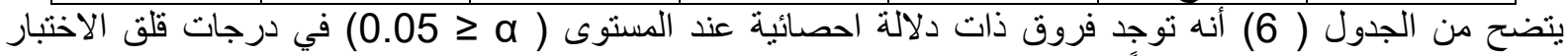

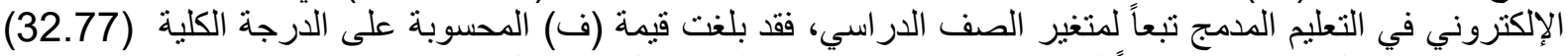

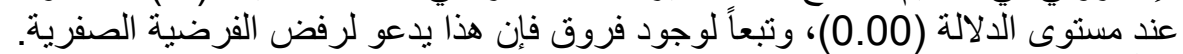

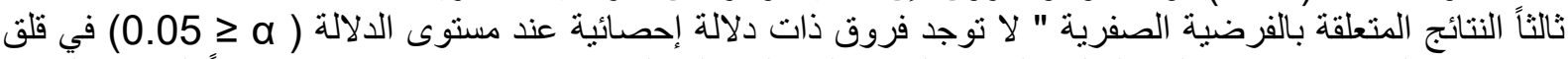
الاختبار الإلكتروني في عملية التعليم المدمج لاى طلنة النية المرحلة المتوسطة في مدرسة حطين تبعاً لمتغير الجهاز

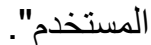

للتحقق من صحة الفرضية نم استخر اج المتوسطات الحسابية والانحر افات المعيارية لدرجة قلق الاختبار الإلكتروني تبعاً

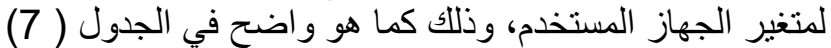

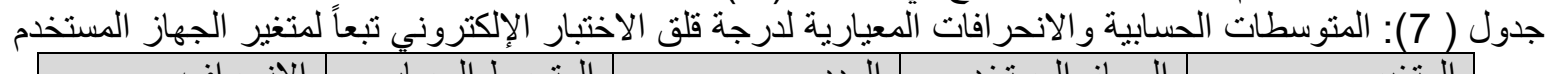

\begin{tabular}{|c|c|c|c|c|}
\hline المعياري الانحر & المتوسط الحسابي & العدد & الجهاز المستخدم & المتغير \\
\hline 0.78 & 3.57 & 194 & جو ال & \multirow[t]{4}{*}{ الجهاز المستخدم } \\
\hline 0.86 & 3.66 & 35 & لاب توب & \\
\hline 0.67 & 4.18 & 32 & كمبيوتر & \\
\hline 0.59 & 3.91 & 8 & تابلت & \\
\hline
\end{tabular}

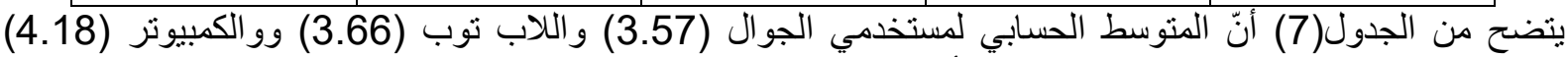
و التابلتح(3.91)هي نسب منقاربة فيما عدا أكبر ها كانت لجهاز الكمبيوتر .ولفحص الفرضية استخرجت نتائج تحليل

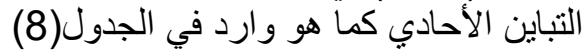

جدول ( 8): نتائج اختبار تحليل التباين الأحادي (One way Anova) للفروق في درجات قلق الاختبار الإلكتروني

\begin{tabular}{|c|c|c|c|c|c|c|}
\hline الإحصائية & قالمحسوبة ف & متوسط & الحرجية & مجموع المربعات & مصدر التباين & \\
\hline \multirow{3}{*}{0.01} & \multirow{3}{*}{5.869} & 3.523 & 3 & 10.57 & بين المجمو عات & \multirow{3}{*}{ المستخدم } \\
\hline & & 0.600 & 263 & 157.88 & داخل المجمو عات & \\
\hline & & & 266 & 168.45 & المجموع & \\
\hline
\end{tabular}




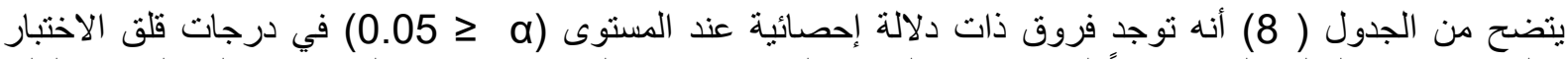

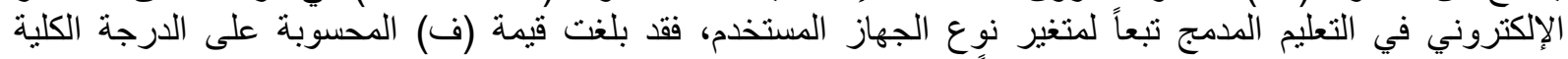

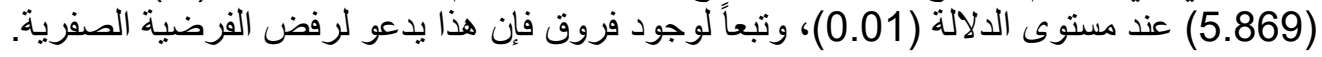

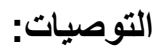
- - اعتماد برنامج إرشادي مدمج داعم للطلاب قبل الامتحان للتخفيف من القلق و التوتر عند الطالب.

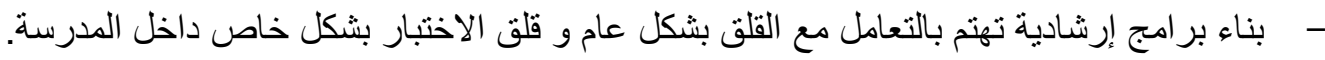

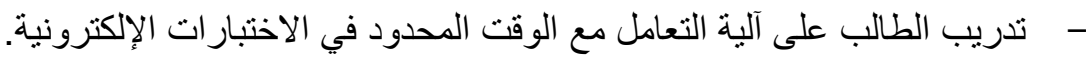

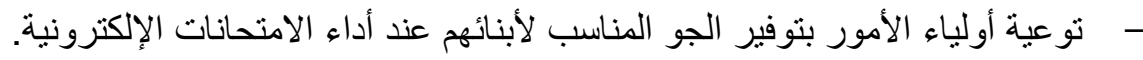

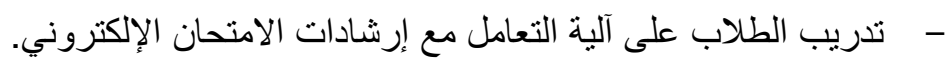

- - تدريب الطلاب على آلية التعامل مع أدوات المنصة المبني عليها الامتحان الإلكتروني.

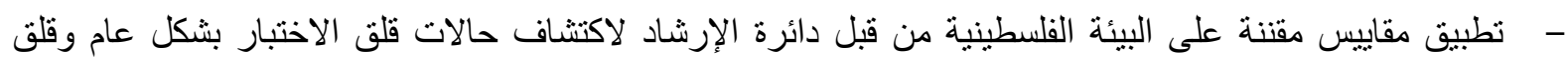

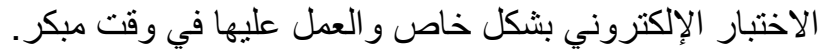

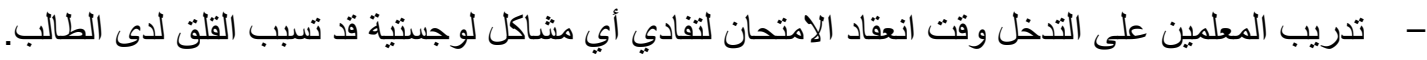

دراسات مقترحة: - - دراسة الفروق بين الجنسين لقلق الاختبار الإلكتروني في عملية التعليم المدمج.

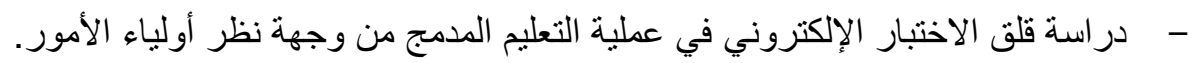

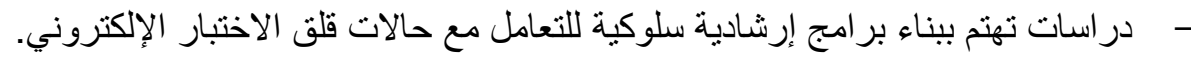

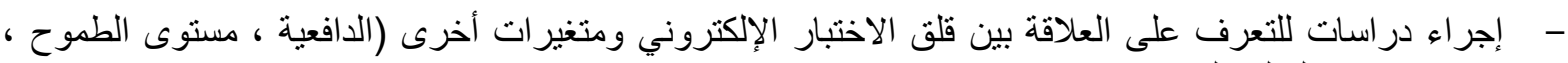
الإنجاز .. مع التعليم المدمج). - در اسة علاقة قلق الاختبار الإلكتروني بميول تحديد الاتجاه الأكاديمي (علمي، أدبي، تجاري .. ).

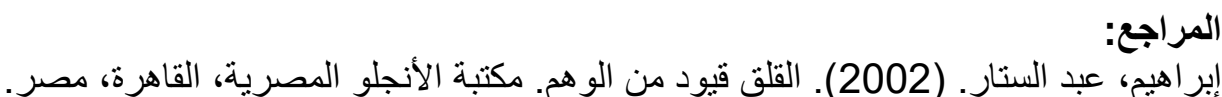

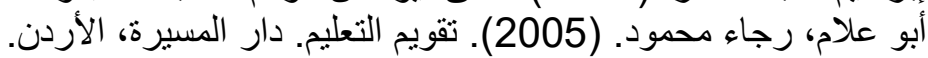

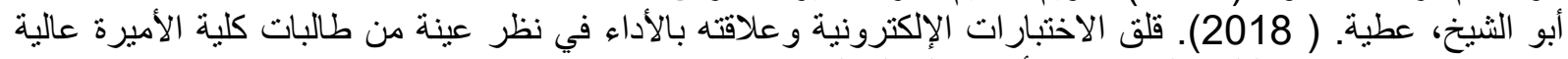

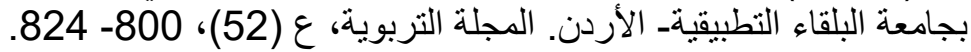

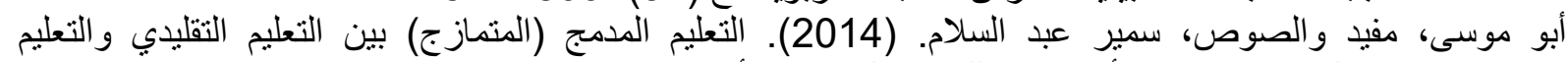

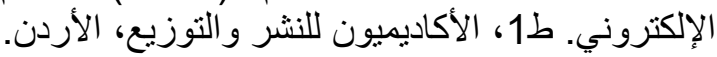

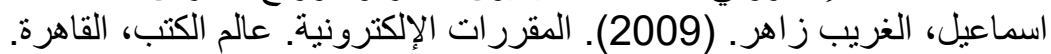

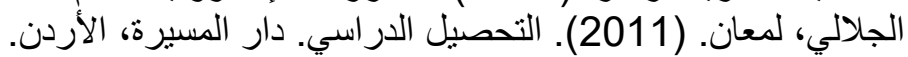

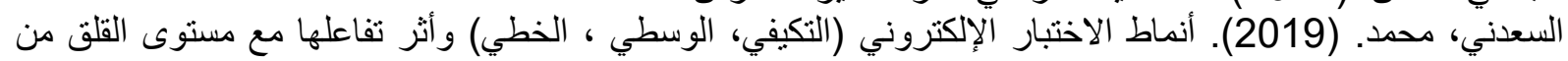

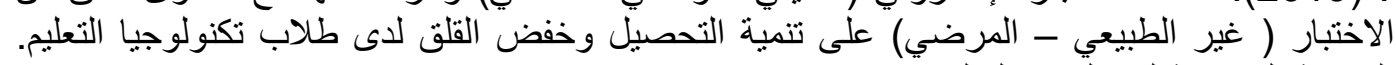

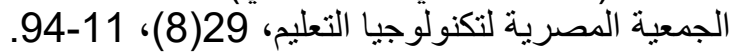

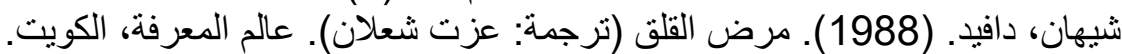

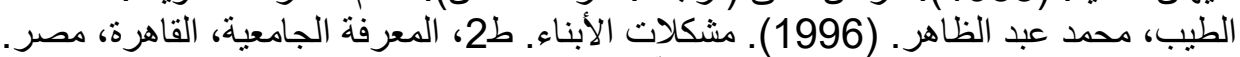

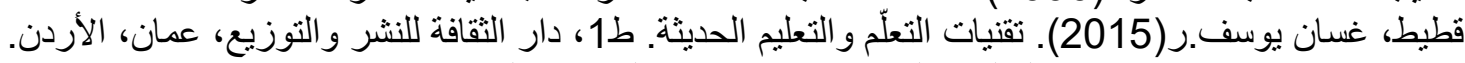

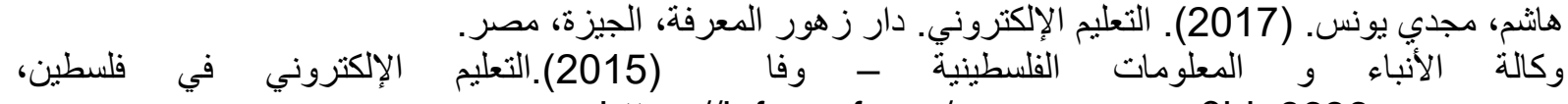
https://info.wafa.ps/ar_page.aspx?id=9636 
Damer, D.E., \& Melendres, L. t. (2011) Tackling test anxiety: Agroup for college students. The Journal for Specialists in Group Work, 36(3), 163-177.

Javanbakht, N., \& Hadian, M. (2014) The effects of test anxiety on learners reading test performance. Procedia- Social and Behavioral Sciences, 98, 775-783.

Wang, H. \& Shin,C. (2010) Comparability of Computerized Adaptive and PaperPencil Tests. Pearson/ Test, Measurement \& Research Services Bulletin. 13.

Whitelock, D. \& Jelfs, A. (2003) Editorial: Journal of Educational Media Special Issue on Blended Learning, Journal of Educational Media, 28 (2-3), 99-100. 